\title{
Articulações em Performance
}

\author{
Evelyn Martina Schuler Zea
}

Universidade Federal de Santa Catarina, Florianópolis, Brasil E-mail: evelynsz@gmail.com

\section{Luciana Hartmann}

Universidade de Brasília, Brasília, Brasil

E-mail: luhartm@yahoo.com.br

\section{Scott Head}

Universidade Federal de Santa Catarina, Florianópolis, Brasil E-mail: head.sc@gmail.com

\section{Vânia Z. Cardoso}

Universidade Federal de Santa Catarina, Florianópolis, Brasil

E-mail:vaniazcardoso@gmail.com 



\section{Colóquio Antropologias em Performance}

m maio de 2009, o Grupo de Estudos em Oralidade e Performance
(Gesto) organizou o I Colóquio Antropologias em Performance, na Universidade Federal de Santa Catarina. ${ }^{1}$ Para aquele primeiro encontro, foi proposta uma reflexão sobre a complexidade de influências crítico-teóricas do campo de estudos em performance, buscando explorar justamente seu potencial como perspectiva crítica para a análise da vida social em todas as suas dimensões. Em contraponto à marcada influência da produção teórica sobre ritos, rituais e teatro nos estudos em performance no Brasil, o I Colóquio propôs reunir também um conjunto de pesquisadores cujo trabalho era oriundo de um diálogo com a rica produção dos estudos de "arte verbal".

Em consonância com essa abertura para os estudos de linguagem, o encontro foi aberto com a palestra de Richard Bauman, dando assim início a uma série de mesas em que se buscava refletir sobre os sentidos e as implicações dos diversos usos dos conceitos de "performance" e "performativo". Longe de situar os estudos em performance dentro de um campo em particular, o que aquele I Colóquio apontou foi para a confluência de diversas preocupações teóricas e etnográficas e para 
a configuração de um heterogêneo leque de fontes e perspectivas disciplinares em torno da performance.

Em continuidade com essa ideia de propor discussões que ponham em diálogo as múltiplas temáticas que atravessam os trabalhos de diversos pesquisadores e que permitam articular uma reflexão em torno da performance e da antropologia, o Gesto organizou o II Colóquio Antropologias em Performance, em abril de 2012, também na Universidade Federal de Santa Catarina. A realização desse segundo Colóquio contou com o apoio da UFSC e do Instituto Brasil Plural (INCT/CNPq).

\section{A figura da articulação no II Colóquio}

Nesse II Colóquio, organizado por Evelyn Schuler Zea, Luciana Hartmann, Scott Head e Vânia Cardoso, propusemos um encontro que se movimentasse através das articulações entre antropologia e performance, sem reduzi-las a uma 'antropologia da performance' e muito menos a uma 'performance da antropologia'. Nos refletores dessa proposta aparecem processos coreográficos, narrativos ou sonoro-imagéticos liminares, aqueles que transitam em direção a um outro e perpassam fronteiras disciplinares. Esses processos desenham trajetórias que não se completam em si mesmas e que, nessa medida, evocam a figura da articulação, a qual, por sua vez, já desde sua etimologia sugere uma relação de parte a parte. Articulações implicam menos uma separação a ser atravessada e mais uma tessitura intersticial a ser tensionada - assim como a cartilagem e os ligamentos na juntura dos ossos ou o plasma multissensorial e sinestésico da experiência.

A proposta do Colóquio poderia igualmente apelar a articulações sonoras: longe de se reduzir a uma oposição entre articulações musicais e aquelas da linguagem (ou linguagem/corpo), a articulação de som, sentido e sentimento é capaz de acontecer por meio da voz. É igualmente por meio dessa e outras matérias ressoantes que se dá voz tanto à musicalidade da linguagem quanto à linguagem da música.

A voz, por sua vez, dá corpo às palavras que enuncia e às histórias que conta, assim como essas palavras narradas articulam o sentido do mundo com o mundo dos sentidos. Se as narrativas assim articuladas 
nos levam para longe de meras distinções entre fato e ficção, realidade e imaginário, elas também reverberaram com percepções de que o encenado, imaginado, ficcionalizado, carrega em si uma concretude.

Entre diversas formas de transação, o conceito de articulação introduz então novos sentidos, ressonâncias, flexões e (dis)junções políticas, cuja proliferação por meios (inerentemente?) indisciplinados se procurava rastrear.

Artistas e pesquisadores de diversas instituições do Brasil, da Argentina, da Alemanha e dos Estados Unidos foram convidados a apresentar trabalhos a partir dessa proposta. As mesas "Inscrições Performáticas", "Articulações em Movimento", "Articulações em Risco" e "Articulações Sonoras", realizadas durante os três dias do Colóquio, reuniram 16 trabalhos divididos em quatro seções temáticas, precedidas das apresentações dos três palestrantes convidados: Gabriele Brandstetter, do International Centre Interweaving Performance Cultures da Universidade Livre de Berlim; André Lepecki, da Performance Studies, da Tisch School of the Arts da Universidade de Nova Iorque; e Eleonora Fabião, do curso de Direção Teatral da Universidade Federal do Rio de Janeiro.

Em sua conferência de abertura, Entrelaçamentos culturais em dança, Gabriele Brandstetter trata, através do videoexemplo que mostra uma "performance-lecture" entre um dançarino de Bangkok (Pichet Klunchun) e um dançarino de Paris (Jérôme Bel), do conceito de entrelaçamentos culturais, propondo uma leitura política desses modos de interação. Para tal, ela apresenta uma das ideias fundamentais do Centro de Pesquisa Interweaving Performance Cultures (criado há dois anos em Berlim), que consiste em refletir sobre os modos em que culturas foram ou são entrelaçadas, tomando como hipótese que processos de entrelaçamentos não levam à homogeneização (no sentido das teorias da globalização ou da hibridização), mas sim que criam uma forte diversificação. Nesse sentido, Brandstetter descreve o conceito de entrelaçamento como modo de articulação aberta para novas diferenças, inclusive produzindo-as e tornando-as visíveis. Assim, o teatro, a performance e a dança oferecem um palco para atores e espectadores que se percebem, nessa situação pública, capazes de abordar fenômenos sociais e criticá-los, transformá-los, estilizá-los e também negá-los. 
Na segunda conferência do Colóquio, Coreopolítica e coreopolícia, André Lepecki aborda de que modo "coreografia" pode ser usada simultaneamente como prática política e como enquadramento teórico que articula performances de mobilidade e mobilização em cenários urbanos de contestação. Tomando como ponto de partida práticas artísticas que implicam diretamente as tensões sociais que formam e performam as fissuras do urbano, Lepecki propõe que o sujeito que emerge dessas rachaduras, movendo-se para além e aquém dos passos que lhe teriam sido pré-atribuídos, é o sujeito político pleno, para quem a questão fundamental é como recapturar uma nova ideia, uma nova imagem e uma nova noção coreográfica de um movimento verdadeiramente político.

Na última conferência, Série Precários: performance, corpo, cidade, Eleonora Fabião apresenta a Peça Linha, uma das performances que compõem a série de ações que ela vem realizando em ruas e praças movimentadas de grandes centros urbanos e que são, como enfatiza, dissonantes o suficiente para desnaturalizar corpo, relações e meio e, ao mesmo tempo, inclusivas, demoradas e precárias o bastante para que não se tornem espetaculares. A Peça Linha-que acontece na cidade de Nova Iorque exatamente nove anos após o 11 de setembro de 2001 e um ano antes do Occupy Wall Street Movement 2011 - inicia com um telefonema pedindo para marcar um encontro com um desconhecido para conversar com o estranho na intimidade da casa dele (que, no final do encontro, indica outra pessoa de sua escolha, aquela que dará continuidade à Linha). Trata-se, nas palavras de Fabião, de explorar o vaivém, o entra e sai, o dentro e fora, a casa e a rua que literalizam o entrecruzamento privado-público e enfatizam a importância do investimento alto na poética e na política do encontro nesse movimento para a criação de amizades performativas que podem ser concebidas como o oposto de cometer um crime: um anticrime. Fabião propõe que cada ação realizada foi um anticrime cometido em nome de uma reflexão - altamente relevante não só, mas especialmente numa cidade como Nova Iorque depois do 11 de setembro de 2001 - sobre o comportamento numa sociedade de controle, articulando os temas cidadania e amizade em nosso contexto sociopolítico e, para tal, valorizando o vigor político e a potência estética da precariedade da performance. 
Além dessas apresentações, diversas performances ocorreram ao longo do Colóquio. Dentre os artistas convidados, o ator, diretor, dramaturgo e professor de teatro Graça Veloso abriu o Colóquio no dia 11 de abril de 2012, com a apresentação de sua peça Inderna de Intão, no Teatro da UFSC. Segundo Graça Veloso, Inderna de Intão conta a história de uma velha sertaneja, viúva, que, desde que seu marido se foi, passou a conviver com os fantasmas de seu passado, contando as estórias de como seus animais morreram, como conhecidos desapareceram ou como perdeu uma ou outra coisa que amava. Para o ator, esse trabalho é um mergulho na alma interiorana do estado de Goiás, com seus causos cômicos e suas religiosidades.

Ao longo do Colóquio, o público era 'recebido' pelo vídeo interativo Hi!, do artista plástico Diego de los Campos, que também apresentou sua videoarte em stop motion, com os trabalhos Homem carne e Homem pão; e com a série Simpatia, composta dos trabalhos Pequena tentativa desvanecente; Sobre como digerir pensamentos, Purge e Exercício para comprimir pensamentos. ${ }^{2}$ Comentando seu trabalho, Diego de los Campos nos diz que na série Simpatia trabalha "o autorretrato, relacionando objetos ou manipulação digital com processos internos ou sensações recorrentes e sem solução. A performance é a expressão do rosto frente à câmera e do material utilizado como forma de exteriorizar esses processos". Quanto aos trabalhos Homens carne e pão, "a técnica é o timelapse, e a performance é da forma em sua eminente deteriorização e colapso através do tempo, que na animação é comprimido".

Fechando o Colóquio, a professora e contadora de histórias Gilka Girardello narrou Uma história em busca de quem a escute, em que a busca da narradora por alguém que ouça o que ela tem para contar descortina um mundo de forças mágicas onde a ouvinte se torna personagem da própria história narrada.

A Seção Temática aqui publicada reúne grande parte dos trabalhos apresentados nesse II Colóquio, deixando entrever um pouco da riqueza das discussões suscitadas pelas múltiplas articulações entre os diversos trabalhos. Há que se destacar que a presença de um público muito participativo, composto não só de pessoas ligadas à universidade, mas também de atores, dançarinos, escritores e outros artistas, além 
de antropólogos, trouxe distintos e provocadores olhares para essas articulações. Vários dos textos aqui publicados, alguns com novos títulos, incluem em suas elaborações algo dessas discussões. Dentre os vários trabalhos apresentados nas mesas, alguns não foram incluídos nesta coletânea, pois estão no prelo em outras publicação. O mesmo ocorre com a palestra de Eleonora Fabião, a qual fará parte de um novo livro, reunindo vários de seus trabalhos. ${ }^{3}$

Dos trabalhos apresentados na mesa "Inscrições Performáticas", publicamos apenas La eficacia ritual de las performances en y desde los cuerpos, de Silvia Citro, da Universidad de Buenos Aires, em que ela analisa processos envolvidos na eficácia ritual de performances festivas a partir de uma perspectiva interdisciplinar que - além de referências teóricas da Antropologia, da Sociologia, da Filosofia, da Psicanálise e, mais recentemente, das Neurociências - inclui as etnografias que ela realizou em distintos contextos rituais e artísticos, assim como sua própria experiência como performer no campo da música e da dança. Enfatizando o papel da música e da corporeidade na geração de intensos sentimentos e emoções, Citro destaca como, através da repetição de um prazer coletivo encarnado, o processo ritual promove um tipo peculiar de docilidade. Ela se refere em particular ao caso dos rituais do Evangelho das "igrejas aborígenes" dos Tobas do Chaco argentino, analisando a eficácia que atribuem ao "gozo/ntonaGak", um estado de "alegria" e emoção intensa que promove "força", "poder" e "saúde" e que se alcança, principalmente, através da dança e do canto coletivos e da criativa articulação entre práticas do xamanismo toba, do evangelismo e dos tratamentos da medicina ocidental.

A segunda mesa, "Articulações em Movimento", foi aberta com o trabalho Água e pedra: texturas de um corpo social em mudança, de Ida Mara Feire, da Universidade Federal de Santa Catarina, articulado com a apresentação da videodança Stone Dance. A partir desse ensaio de etnografia visual, que foi filmado no final do ano em que a autora morou com sua filha na Cidade do Cabo, na África do Sul, e cujo título foi inspirado por um monumento a crianças mortas durante o regime de apartheid, salientam-se algumas das texturas sociais e sensoriais da sociedade pós-apartheid. Além de comentar o filme apresentado, o 
próprio texto da autora oferece 'imagens' tanto poéticas quanto teóricas e etnograficamente informadas de variadas noções de temporalidade sugeridas no vídeo: como o tempo presente na infância, na percepção do outro e na experiência com a cegueira.

Se a comunicação de Ida Mara Freire já evocou a 'dança' entre imagens e palavras presentes não só no filme, mas igualmente no próprio texto apresentado, essa preocupação implicitamente coreográfica materializou-se de forma mais direta na apresentação que veio em seguida, Falar-fazer antropologia: uma experimentação etnográfica do corpo na capoeira Angola, de Heloisa Gravina, da Universidade Luterana. Através do procedimento conhecido em dança como "falar-fazer", a autora ressalta o aspecto performativo da construção do conhecimento e sua dimensão corporal - neste caso, com respeito ao campo empírico da capoeira Angola. Na apresentação oral, a principal questão explorada desse modo foi: que formas podemos adotar para falar de performance, uma vez que assumimos que, a partir desse paradigma, forma e conteúdo se constituem mutuamente? Ao voltar-se para a versão escrita, que reencena textualmente as falas, os gestos, as sonoridades e os movimentos que compuseram a apresentação (e o debate que se seguiu), outra pergunta acrescenta-se à original: que formas adotamos para escrever sobre (e a partir da) performance?

A terceira mesa, "Articulações em Risco", foi aberta por Luciana Hartmann, da Universidade de Brasília, com a apresentação de "Não sendo mentira, são sempre verdade": aprendizagem e transmissão da mentira entre contadores de causos. Nesse trabalho, Hartmann trata dos processos de aprendizagem, transmissão e recepção da mentira na região fronteiriça do Sul do Brasil, onde frequentemente "contar causos" e "contar mentiras" são tratados como sinônimos. Observando, em vários anos de pesquisa de campo, que a mentira é performatizada na forma de um desafio que estabelece um jogo entre contadores e ouvintes, Hartmann procura compreendê-la desde a articulação de uma aprendizagem situada como o resultado de um processo colaborativo que emerge de situações e contextos específicos. Para compreender melhor as ambiguidades, as dúvidas, as ironias e as brincadeiras expressas na mentira, Hartmann nos diz que é preciso participar de 
uma "comunidade de prática" para que possamos aprender a ouvir, a contar e, quem sabe, aprender a mentir...

Em seguida, Maria Laura Viveiros de Castro Cavalcanti, da Universidade Federal do Rio de Janeiro, apresentou Formas do efêmero: alegorias em performances rituais. O trabalho toma como seu enfoque os grandes carros decorados conhecidos como "alegorias", que integram o desenrolar das performances rituais contemporâneas do Boi-Bumbá de Parintins, Amazonas, e do Carnaval das escolas de samba no Rio de Janeiro. Construídas para a fruição ritual, tais alegorias produzem efeitos decisivos na dinâmica das apresentações festivas anuais. Assumindo o ponto de vista do espectador, e baseado em pesquisas etnográficas, o texto articula as distintas modalidades de ação das alegorias, em especial a produção diferenciada do almejado efeito de maravilhamento e os riscos aí implicados.

Assim como o enfoque nas alegorias carnavalescas do artigo anterior, o trabalho Bonecos da Rua do Porto: performance, mimesis e memória involuntária, de John C. Dawsey, da Universidade de São Paulo, trata de objetos construídos e dotados com a agência e a potência de produzir maravilhamento - objetos que são ao mesmo tempo colocados em risco. Só que nesse caso, os objetos em questão consistem em "bonecos pescadores", bonecos feitos de palha, de tamanho e forma humana, colocados às margens do rio em Piracicaba (SP). A partir de um olhar informado e inspirado particularmente pelos escritos de Walter Benjamin, o autor lê a presença desses bonecos como emergindo da memória involuntária da cidade e resultando em efeitos de montagem perturbadores. Dessa perspectiva, o criador dos bonecos, um barranqueiro e catador de lixo conhecido como "Elias dos Bonecos", reúne e transforma os resíduos de uma enxurrada chamada "progresso". Desse modo, o artigo aponta para o campo mimético formado entre tais bonecos e os barranqueiros que povoam a Rua do Porto: ressalte-se o papel dos bonecos tanto na revitalização da determinação dos barranqueiros de não saírem de lá quanto na renovação dos princípios de reciprocidade a partir dos quais se articulam a vida social e as relações com o rio.

Fechando as quatro mesas, o trabalho de Ana Lucia Marques Camargo Ferraz, da Universidade Federal Fluminense, A aprendizagem no 
samba: notas para o estudo de intensidades numa iniciação à etnomusicologia, deu início às apresentações reunidas em "Articulações Sonoras". Ao etnografar a aprendizagem na música popular entre jovens de classes trabalhadoras, a autora traz os discursos sobre o modo de aprender "de ouvido", que "tira a música", expondo saberes e práticas que envolvem a constituição do campo do samba "de raiz" ou "da velha guarda". Ao contrário dos estudos que relacionam o samba à identidade nacional brasileira, Ferraz busca uma articulação de suas particularidades e especificidades no tempo e nos corpos de seus praticantes.

Nesta mesma mesa, Roberto Marques, da Universidade Regional do Cariri, apresentou os instigantes Usos do som e instauração de paisagens sonoras nas festas de forró eletrônico. A partir de trabalho etnográfico realizado nas festas de forró eletrônico no Cariri (CE), o autor utiliza a noção de paisagem sonora para refletir sobre as múltiplas possibilidades criativas de alteração de si conferidas pela música e pela festa. A ideia de festa como sonoridade instaurada permite que se observe não apenas o conteúdo específico desses eventos, mas uma forma de articulação com os corpos e os pensamentos. Enfocando as performances e as narrativas dos indivíduos que interagem, falam e dançam "sob os holofotes do forró eletrônico", Roberto Marques fala de Luana e Alexandre, do forró eletrônico e também do Cariri, esse "sertão entrefronteiras prenhe de picadas e veredas".

Já María Eugenia Domínguez, da Universidade Federal de Santa Catarina, em Irreverência e tradição numa orquestra de tango: a versão como transgressão, discute como a apropriação de antigos temas musicais, que tem se revelado uma prática frequente entre artistas do Carnaval e músicos diversos da região do Rio da Prata, tem sido articulada na elaboração de novas canções. Essas versões irreverentes e transgressoras, de acordo com a autora, como as que transformam a murga (um gênero considerado artisticamente menor) em tango, desestabilizam os limites e as hierarquias, rompendo com gêneros e categoria sociais.

Encerrando a mesa, a articulação entre Deise Lucy Oliveira Montardo (UFAM) e Hans Denis Schneider (UFSC/Fotografologia) desembocou na apresentação de Uma etnofotografia do Festival Cultural das Tribos Indígenas do Alto Rio Negro/AM (Festribal). Os autores, através 
de registros fotográficos, discutem a pertinência de usar a ideia de representação para tratar desse Festival do qual participam indígenas e não indígenas, que envolve uma disputa entre duas agremiações que levam denominação de etnias e que é realizado nessa que é considerada uma das cidades mais indígenas do país. Da mesma forma que vários trabalhos apresentados ao longo do Colóquio, mais do que apenas representar uma performance, as imagens aparecem aqui, elas mesmas, como performance.

Os textos aqui reunidos formam, de certa maneira, uma "série precária", para tomar emprestada a expressão de Eleonora Fabião. Esperamos que suas reverberações possam tensionar a própria tessitura das antropologias em performance e levar a novas articulações...

\section{Notas:}

1 Coordenado por Esther Jean Langdon, Luciana Hartmann e Vânia Z. Cardoso, o I Colóquio Antropologias em Performance foi aberto com a conferência de Richard Bauman e contou com a participação de 18 outros pesquisadores da antropologia, das artes cênicas e da música. O programa do evento e os trabalhos completos apresentados encontram-se disponíveis em <http://www.gestoufsc.net84.net> e um grupo de trabalhos foi publicado na Ilha: Revista de Antropologia, volume 11, 2010. Esse volume está disponível em <http://www.periodicos.ufsc.br/index.php/ ilha/issue/view/1646>.

2 Os trabalhos de Diego de los Campos estão disponíveis em vários sítios da internet, mas estão completos em <http://issuu.com/deloscampos $>$.

3 Estão ausentes na coletânea ora apresentada os trabalhos Perspectiva xamânica: relações entre rito, narrativa e arte gráfica, de Esther Jean Langdon (UFSC), Transformance: 0 início da iniciação xamânica e outros gestos entre tradução e performance no Norte Amazônico, de Evelyn Schuler Zea (UFSC), e Performance em foco: contrapontos e contribuições de Ruth Finnegan e Paul Zumthor para a poesia oral, de Frederico Fernandes (UEL), que fizeram parte da mesa "Inscrições Performáticas"; Girando entre gestos: interrupção como fonte do fluir, de Scott Head (UFSC) e Vânia Cardoso (UFSC), que fez parte da mesa "Articulações em Movimento"; e Com o inimigo na corda bamba: conflitos e a performance do equilíbrio, de Allan de Paula Oliveira (UNIOESTE), apresentado na mesa "Articulações em Risco". 